\title{
Impact of Modelling and Simulation in Solving Complex Problems in First Year Engineering Course
}

\author{
Madhu Asundi ${ }^{1}$, Dr. Rohit Kandakatla ${ }^{1,2}$, Dr. Gopalkrishna Joshi ${ }^{3}$ \\ ${ }^{1}$ Centre for Engineering Education Research, KLE Technological University, Hubballi \\ ${ }^{2}$ Department of Electronics and Communication, KGR College of Engineering, Hyderabad \\ ${ }^{3}$ Executive Director, Karnataka State Higher Education Council, Bangalore \\ ${ }^{1}$ madhu.asundi@kletech.ac.in \\ ${ }^{2}$ rohit.kanadakatla@kgr.ac.in \\ ${ }^{3}$ ghjoshi@kshec.ac.in
}

\begin{abstract}
Introduction of modelling and simulation experiences has been a widely accepted practice in the engineering education system. One of the key motivation to provide students with modelling and simulation opportunities is to equip them with the knowledge and skills to utilize modern tools, which are widely used in the industry for complex problem solving. There have been many studies conducted to understand the student's ability to solve complex problems by adopting various practices and technology tools at $2^{\text {nd }}$ or $3^{\text {rd }}$ year of undergraduate engineering program.

In this study, one such experience for first year undergraduate students was conducted. Modelling and simulation was introduced in to a course named engineering exploration, to try and understand its effect in complex problem solving. This course is offered to all first-year students at KLE Technological University.

An experimental design for the study was used where 64 multidisciplinary projects were assigned to the control and experimental group. The experimental group was introduced with MATLAB-Simulink tool. At the end of the semester, each of the projects in both the groups were analysed to calculate the complexity of the projects. Descriptive statistics was used to compare the mean score of the complexity of the projects between these groups and to understand the effect of modelling and simulation experiences on students' complex problem solving ability. The results from the study would be helpful for undergraduate engineering educators to develop the problem -solving skills among first-year engineering students
\end{abstract}

Keywords: Complex problem solving, problem solving, modelling and simulation.

\section{Corresponding Author}

Madhu Asundi, Centre for engineering Education Research, KLE Technological University. Hubballi

madhu.asundi@kletech.ac.in

\section{Introduction}

Due to the current need at workplace to solve problems and the vast development in the complexity of technologies being used in daily life, there is need to equip future professionals with complex problem solving (CPS) skills. These skills are essential to be successful at work and to be able to interact with dynamic system that are quite complex in nature (Greiff et al., 2013; Hung, 2013). In order to build these skills among students, engineering educators in the past decade have experimented and researched about various pedagogical and instructional designs that are aligned to complex problem-solving process in engineering. (Greiff et al., 2013)

Prior research on CPS involved measuring the CPS by creating micro world simulations to analyse learner's strategic and decision making skills, assigning problems to students to observe their cognitive and non-cognitive skills (Dorner and Funke, 2017; Funke, 1988), modelling and simulation practices to aid and test students inquiry learning, and problem solving skills and many other practices to analyse problem solving skills of the students (Brophy et al., 2013; Magna and Jong, 2018; Magna et al, 2017). Modelling and simulation is one such practice to help engage students in understanding the complex phenomenon of any given problem in science and engineering (magna, 2017). Modelling and simulation practices in education offer enormous benefits in students' ability to understand and solve problems. Therefore this practice is required to be integrated as part of the curricula along with effective pedagogical method and learning strategies (magna, 2017), to further explore unknown influential factors that modelling and simulation has on students' learning.

This study focuses on one such effort to understand the modelling and simulation experiences on students' ability to solve complex problems as part of a first-year engineering course called Engineering Exploration with the guiding research question:

What influence does modelling and simulation has on complexity of the course project, carried out by first year undergraduates?

Further sections are organized by first providing the literature survey on complex problem solving and modelling and simulation practices in engineering education, followed by context of the this study carried out on, theoretical background, methods of data collection, analysis and finally concluding with results.

\section{Literature Review}




\section{A. Complex problem solving}

There have been many studies carried out to understand what complex problem solving is and what constitutes complex problem solving. However, there is no one single definition for CPS. In most of the literature, it is stated that "CPS is a barrier between the start state and the goal state." (Voskoglou and Buckly, 2012). These barriers may be difficulty in problem, desired solution, cognitive and noncognitive skills of the solver, and difficulty in the problemsolving process.

Research in CPS was carried out in different facets which include cognitive process, inter individual differences, system factors, psychometric approach, and experimental approach (Dorner and Funke, 2017). According to Jonnassen and Hung (2015), two factors contribute to the problem difficulty 1. Factors internal to the solver such as domain knowledge, experience, reasoning skill, decision making, ability to work in a dynamic situation, or with dynamic systems, application of knowledge and many others and 2. External factors which include nature of the problem, level of abstraction, and continuity involved in the process.

Problems are complex when they are ill-defined, have no clearly defined goals, and have multiple solutions (Dorner and Funke, 2017). Complexity in such situations is commonly measured via dynamic systems. The nature of any complex system are (i) complexity that involve many variables in the system, (ii) connectivity among these variables, (iii) dynamics of the system (iv) intransperency of the variables involved, and (v) Polytely: existence of many goals (Funke, 2012).

Aligned to this, Jonnassen and Hung (2015) have listed various parameters that define the complexity: i) breadth of the knowledge required, ii) attainment level of domain knowledge, iii) intricacy of the problem-solution procedure, iv) relational complexity v) structuredness of the problem which includes: a) unknown problem space, b) multiple interpretation of the problem, c)dynamic nature of the variables involved, d) degree of interdisciplinary knowledge required, and e) uncertainty and validation of the goal when multiple solution paths exists

It is observed from the previous work that CPS can also be measured when students can design, build, test, and validate complex systems. To scaffold this process, various pedagogies, instructions, methods, and practices are necessary and new measurements have to be explored.

\section{B. Modelling and simulation}

Over the years simulation has been proven to be the best technological tool that enables students in understanding complex concepts, or phenomena in science and engineering (Lenox et al. 1997). Modelling and simulation refers to various processes involving the representation of model behaviours and prediction about the represented model. Maria (1997) defines modelling as the building of the model to represent the working of the system and simulation corresponding to reconfiguration and exploration of the system.
Magna (2017) has conducted a study on identifying required practices of modelling and simulation in graduate and undergraduate levels by collecting data from 18 academic experts and 19 industry experts. The outcome of the study presents a thoughtful guide for the faculty to integrate modelling and simulation in the curriculum and also the framework to establish assessment and instructions.

Magna and Jong (2018) have discussed a detailed thematic survey study on incorporated modelling and simulation practices in engineering education. There themes include i) approach towards course design, ii) pedagogy and practices of implementation of modelling and simulation, and iii) evidence of learning. Outcome of modelling and simulation experience among these themes are : i) enhanced students ability to understand fundamental concepts, demonstration of the acquired knowledge, visualization of complex concepts and application of the skills ii) promoted creativity among students, and iii) Supported active learning, inquiry learning, challenge-based learning, project-based learning, and engages students in system's thinking. Author concluded the study by highlighting the lack of rigorous measure to understand the impact of modelling and simulation.

Magna et al. (2011) evaluated the relation among the problem-solving process and literacy of the computational tool in the problem-based computational science course. Results showed that the disposition of the students' projects and computational challenges designed to follow problemsolving phases is used as a form of scaffolding for student learning and their computer literacy. Outcome also suggested the need for different approaches to solve different types of computational challenges.

Brophy et al. (2013) conducted a study to enhance the student abilities to understand deeper level concepts by integrating traditional lecture and simulation laboratories, which are often designed to support the inquiry activities of the students. Results in the study showed the participation in both traditional lectures and laboratories helped recall facts and behaviours of the model, and also represented students' ability to apply the knowledge.

Magna et al. (2017) present the study on disciplinary knowledge gains when students are engaged in modelling and simulation, this study shows that the students benefitted from testing their ideas by running the model several times in the configuration approach.

Shaik et al. (2015) discussed the role of modelling and simulation in student's problem-solving skills. The study uses the IPS framework for solving problems along with modelling and simulation. In this study, the author suggested that modelling and simulation are highly relevant in solving real-world complex problems, and help in problem-solving, and validation of the concepts learned.

Lyon et al. (2019) conducted a thematic study to analyse the cognitive and metacognitive knowledge of students when modelling and simulation are integrated using the adaptive expertise framework for problem-solving. Categories for cognitive and metacognitive were represented into implementation-oriented vs knowledge-oriented and action- 
oriented vs plan-oriented respectively. Results indicated that the action and implementation-oriented category represented qualities of novices whereas the other category represented the qualities of the experts, these results were less conclusive for students in intermediate categories. The author states that regardless of the different processes almost all the students produced working code.

\section{Gaps Identified in Literature}

From the above literature, it is observed that simulation and modelling offers enormous benefits in teaching \& learning depending on the context and objective set for the integration of modelling and simulation as part of the curriculum. Though the effort put by researchers have pointed out several influential factors on students' learning when engaged with modelling and simulation, very less literature is present on: i) Its impact on the PBL courses for solving complex multidisciplinary projects ii) Lack of sufficient rigorous measure to show the impact of modelling and simulation in solving complex problem when integrated as part of the curriculum. Most of these efforts have been implemented for the $2^{\text {nd }}$ or $3^{\text {rd }}$ year of undergraduate engineering program, which results in no engineering problem-solving experiences at first-year engineering

Our effort here is to integrate modelling and simulation practice in the course project phases to enable students to solve complex problems and understand the impact of modelling and simulation effect on complex problemsolving.

\section{Methodology}

This study focuses on modelling and simulation experiences on students' ability to solve complex problems as part of a first-year engineering course

\section{A. Context of the study}

The engineering exploration course is a first-year engineering course at KLE Technological University, which follows project-based learning (PBL) pedagogy. Students apply course learning to their projects which are multidisciplinary (mechatronic systems) in nature as they involve mechanical, control, and electronic elements. The engineering design process is followed to implement the projects.

One of the phases in the design process is implementation, which is split into virtual implementation and physical implementation. During virtual implementation, students do the modelling of the system: Flowchart for control logic, electronic circuitry, and 3D modelling of the system. To understand how simulation practices can influence project implementation, simulation practices were introduced for the control logic.

The experimental group was introduced with MATLAB Simulink software in the course content, to learn and simulate the logic of the mechatronic system. The learnings of the simulation tool were applied to their course project to build and simulate the logic of the system during the virtual implementation phase. The control group modelled the control by writing the flowchart and program for the system.

\section{B. Theoretical Background}

To measure the impact of modelling and simulation in solving complex problems, "relational complexity" proposed by Jonnassen and Hung (2015) was chosen. In CPS complexity can be measured via dynamics in the systems (Funke, 1988; Dorner, 1980; Jonnassen and Hung, 2015).According to the relational complexity, the complexity of any relation can be expressed in terms of number of variables within the relation and interaction between them (Jonnassen and Hung, 2015). Any cognitive process is a function that converts inputs into outputs, a function is a special type of relation. (Halford et al., 1998). Therefore comparison study was done between the control and experimental groups, for the control logic built in each of their project.

Control logic is the core of the system which enables resource utilization and functioning of the system. Using relational complexity theory, the complexity of any control logic can be determined by the number of functions it performs and also the number of resources it can manage. Individual projects were examined to get (i) integration of components in a system, and also the (ii) functionality aspects of the system

\section{Participants}

This study was conducted for the first-year engineering students, undergoing engineering exploration course, 64 teams were chosen for the experiment, each team having team size between 3 to 5 students. 64 teams were divided into 32 experimental group as Simulink users and 32 control groups who used IDE for their implementation. Figure. 1 depicts the overall distribution of student teams selected for both the control group and the experimental group. The need statements given for the students were Agriculture mechanization, Ball launching, Decorative, Disc Throwing, Drill bit dispenser, Floor cleaning and Game machines. The need statements were given to the students at the beginning of the course. These need statements were complex design problems and necessary criterion were set to select these need statements (Mallibhat et al., 2020). Equal number of teams were selected for both IDE and Simulink users except little variation in the Disc throwing and Drill bit dispenser machines. To get good insights about the data after analysis, 64 projects were chosen for the study

\section{Data Collection Procedure}

According to the relational complexity theory, the measurements needed were functionality and component integration aspects of the system. From each team, shown in Figure 1. both the parameters were collected. 


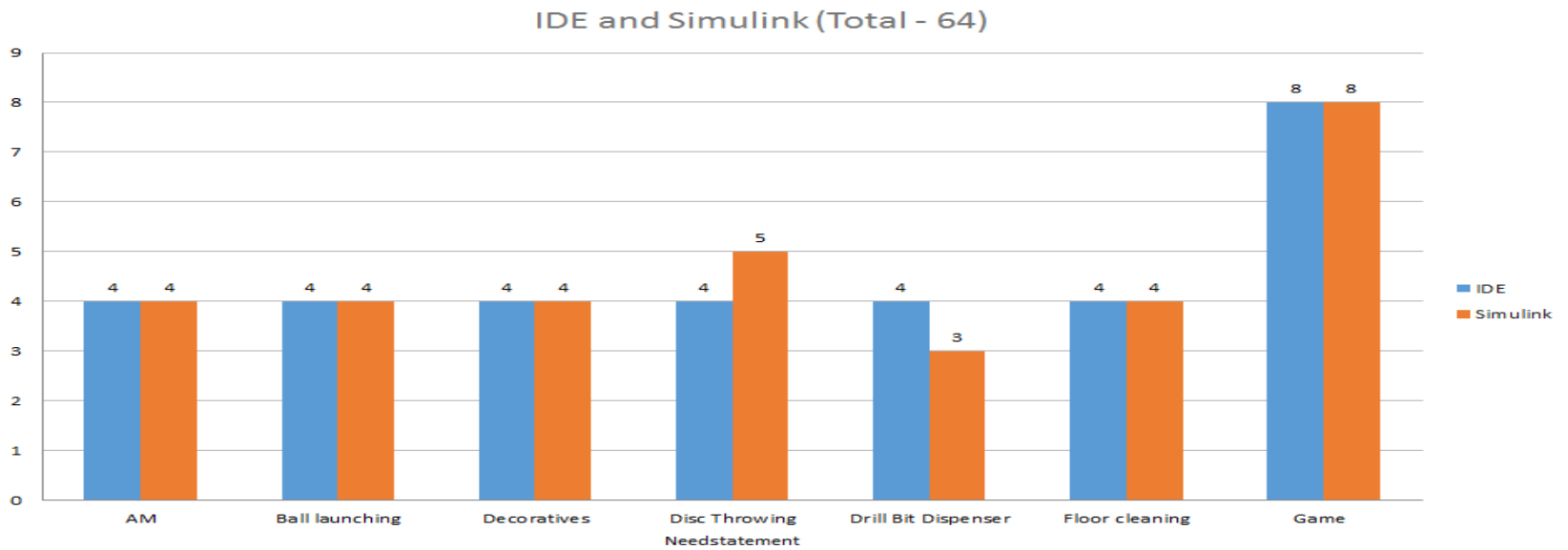

Figure 1. Need statements selected for the data collection

The data collected from each team regarding their project included the following details and were quantitative in nature. This information was collected from direct interaction with the teams over a telephonic conversation.

1. Number of functionalities implemented in the final implementation

2. Number of components integrated in the final implementation

\section{E. Data Analysis Procedure}

For the data collected from both the groups, a comparative study was done using descriptive statistics, and t-test was performed to identify the difference between both of the groups. Excel and python were used as a tool for the analysis of the data and the results are discussed in the following section

\section{Results and Discussion}

Results are organized in two parts, functions implemented and components integrated. In both sections, results present the summary of descriptive statistics and outcomes of the ttest result for both the control and experimental group

\section{A. Functionalities Implemented}

Table 1 summarizes the statistics for both Simulink and IDE users. The mean of the experimental group is 4.56 whereas the control group is 4.71 . The control group has a maximum value of 12 stating the maximum number of functionalities achieved in IDE users is 12 and Simulink 11. The data listed in table 1 summarizes the same. Figure 2 plots the summarized data.

To understand whether there was any difference between the control group and the experimental group, a t-test was performed. The result doesn't provide any significant difference between these groups as the p-value is $>0.05$ (statistic $=0.2652038104483469, \quad \mathrm{p}$-value $=$ $0.7917322389136089)$

Our observation from the analysis is that the difference between these groups were insignificant. This result may be because of the impact of the decisions taken during the design process. Most functions were well defined by students in the earlier stages of the design process, well before the introduction of the modelling and simulation experiences were introduced to the experimental group.

Table 1. Summary of Functionalities Implemented

\begin{tabular}{|l|l|l|}
\hline & Simulink & \multicolumn{1}{c|}{ IDE } \\
\hline Count & 32 & 32 \\
\hline Mean & 4.56 & 4.71 \\
\hline Std & 2.28 & 2.42 \\
\hline Min & 0 & 0 \\
\hline max & 11 & 12 \\
\hline
\end{tabular}

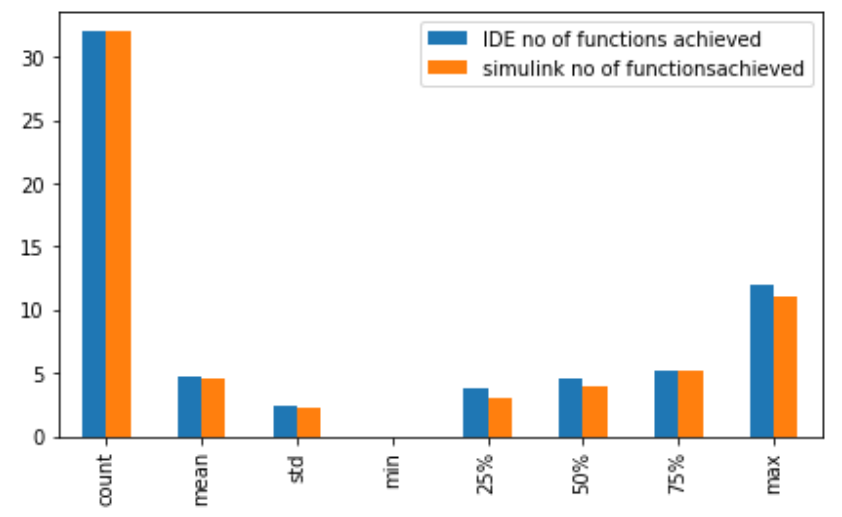

Fig. 2.Summary of Functionalities Implemented

B. Components Integrated

For the components integrated in IDE projects and Simulink projects, overall mean and standard deviation were 6.12, 5.04 and 7.09, 3.04 respectively. We observed that the maximum value for Simulink is 26 , depicting that the maximum components integrated in Simulink projects were higher as compared to 15 in IDE. The plotted graph in Figure 3 gives a summary of the data present in the Table. 2 .

Even though there is no significant difference observed in the t-test, we see that there is some variation in the descriptive statistical analysis. The mean and the maximum 
count value for the Simulink project are higher than the IDE projects.

The decision to select the number of components were taken during the virtual implementation process, after the introduction of the modelling and simulation practice. This may have impacted in the selection of the number of components for their projects due to the continuous testing and evaluation of the control logic in configuration approach (Magna et al, 2017)

Through this result, we can observe that after the introduction of modelling and simulation practice there is some impact in the design choices made. The awareness of the possibility to integrate more number of components into a project was noted through descriptive statistical analysis.

Table 2. Summary of Components Integrated

\begin{tabular}{|l|l|l|}
\hline & Simulink & \multicolumn{1}{|c|}{ IDE } \\
\hline Count & 32 & 32 \\
\hline Mean & 7.09 & 6.12 \\
\hline Std & 5.04 & 3.49 \\
\hline Min & 0 & 0 \\
\hline max & 26 & 15 \\
\hline
\end{tabular}

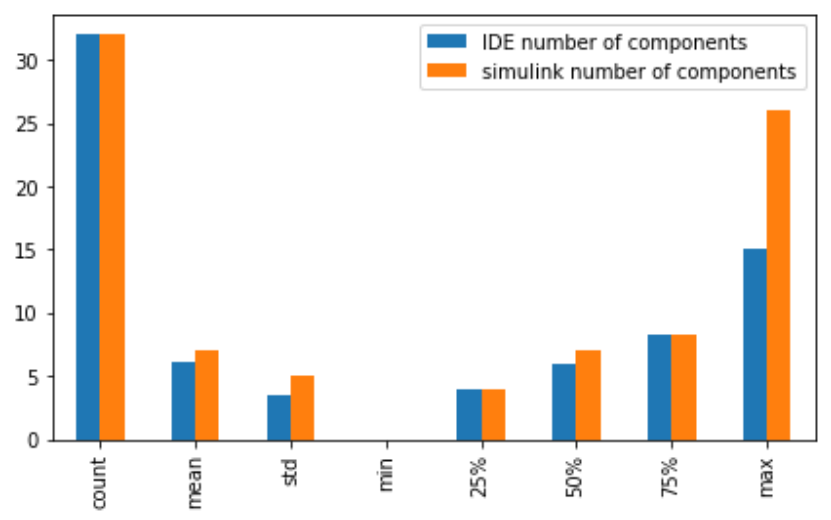

Fig. 3. Summary of Components Integrated

\section{Conclusion}

Introduction of modeling and simulation is inevitable in engineering education as students need to be equipped with necessary knowledge, skills to solve complex problems and use modern tools. They need experience in working with complex modern \& computational tools to solve real-world complex problem that are often encountered in the workplace or the day to day life. When provided with modeling and simulation practice in designing complex systems, it gives students the possibility to experiment, test and understand the system on a deeper level. The experience gained over designing a complex system via modeling and simulation can be transferable to different context and scenarios.

This study was conducted to analyze the students' complex problem solving through the multidisciplinary projects implemented as part of a first-year engineering design based course. The results for the parameter functionalities implemented showed no significant difference between the control and the experimental group, whereas the parameter integration of components indicated the opportunity to experiment in the control logic being designed and ability to make a design choices to integrate various external input and output devices to the system. These were observed in the experimental group. The future scope of the work is to carry out a qualitative study to analyze other parameters of the complex problem solving when engaged in modeling and simulation

\section{Acknowledgement}

We are grateful to Sanjeev Kavale for providing useful resources and support in the beginning of this study, we also thank Nandish Humbi and other CEER(Centre for Engineering Education Research) faculty in helping us during the data collection process.

\section{References}

Greiff, S., Wüstenberg, S., Holt, D. V., Goldhammer, F., \& Funke, J. (2013). Computer-based assessment of complex problem solving: Concept, implementation, and application. Educational Technology Research and Development, 61(3), 407-421.

Hung, W. (2013). Team-based complex problem solving: A collective cognition perspective. Educational Technology Research and Development, 61(3), 365-384.

Dörner, D., \& Funke, J. (2017). Complex problem solving: what it is and what it is not. Frontiers in psychology, 8, 1153. Funke, J. (1988). Using simulation to study complex problem solving: A review of studies in the FRG. Simulation \& Games, 19(3), 277-303.

Brophy, S. P., Magana, A. J., \& Strachan, A. (2013). Lectures and Simulation Laboratories to Improve Learners' Conceptual Understanding. Advances in Engineering Education, 3(3), n3.

Magana, A. J., \& de Jong, T. (2018). Modeling and simulation practices in engineering education. Computer Applications in Engineering Education, 26(4), 731-738.

Magana, A. J., Falk, M. L., Vieira, C., Reese Jr, M. J., Alabi, O., \& Patinet, S. (2017). Affordances and challenges of computational tools for supporting modeling and simulation practices. Computer Applications in Engineering Education, 25(3), 352-375.

Magana, A. J. (2017). Modeling and simulation in engineering education: A learning progression. Journal of Professional Issues in Engineering Education and Practice, 143(4), 04017008.

Voskoglou, M. G., \& Buckley, S. (2012). Problem solving and computational thinking in a learning environment. arXiv preprint arXiv: 1212.0750

Jonassen, D. H., \& Hung, W. (2015). All problems are not equal: Implications for problem-based learning. Essential readings in problem-based learning, 7-41. 
Funke, Joachim, Complex Problem Solving (March 14, 2012). N. M. Seel (Ed.), Encyclopedia of the Sciences of Learning (682-685). Heidelberg: Springer.

Lenox, T. A., Ressler, S. J., O’Neil, R. J., and Conley, C. H. (1997). "Computers in the integrated civil engineering curriculum: A time of transition." Proc., 1997 American Society of Engineering Education Conf., Milwaukee.

Maria, A. (1997). "Introduction to modeling and simulation." Proc., 29th Conf. on Winter Simulation, Atlanta.

Shaikh, U. A., Magana, A. J., Vieira, C., \& Garcia, R. E. (2015, June). An exploratory study of the role of modeling and simulation in supporting or hindering engineering students' problem solving skills. In ASEE Annual Conference \& Exposition.

Magana, A. J., Vasileska, D., \& Ahmed, S. (2011, October). Work in progress-A transparency and scaffolding framework for computational simulation tools. In 2011 Frontiers in Education Conference (FIE)(pp. S4G-1). IEEE.

Lyon, J. A., Magana, A. J., \& Okos, M. R. (2019). Work in progress: Designing modeling-based learning experiences within a capstone engineering course. In Proceedings of the 2019 ASEE Annual Conference \& Exposition.

Dörner, D. (1980). On the difficulties people have in dealing with complexity. Simulation \& Games, 11(1), 87-106.

Mallibhat, Kaushik \& Baligar, Preethi \& Kavale, Sanjeev \& Joshi, Gopalkrishna. (2020). Crafting Design Problems for Project-based Learning in First-year Undergraduate Engineering Education. Educate for the future: PBL, Sustainability and Digitalisation 2020, 181-195

Halford, G. S., Wilson, W. H., \& Phillips, S. (1998). Processing capacity defined by relational complexity: Implications for comparative, developmental, and cognitive psychology. Behavioral and brain sciences, 21(6), 803-831. 